\title{
Kepuasan Masyarakat Terhadap Pelayanan Penyelenggara Haji Dan Umroh Pada Kantor Kementerian Agama Kota Banjarbaru
}

\author{
Hani Awaliyah \\ Kantor Kementerian Agama Kota Banjarbaru, Indonesia \\ e-mail: haniehanie83@gmail.com
}

\begin{abstract}
Abstrak
Kepuasan masyarakat merupakan faktor yang sangat penting untuk menentukan keberhasilan suatu instansi pemerintah dalam memberikan pelayanan kepada masyarakat. Adapun tujuan penelitian ini adalah untuk menganalisis kualitas pelayanan yang diberikan unit layanan Penyelenggara Haji dan Umroh Kantor Kementerian Agama Kota Banjarbaru kepada publik atau masyarakat dan untuk mengetahui tingkat kesesuaian antara kinerja pelayanan dengan harapan atau tingkat kepentingan masyarakat. Penelitian ini merupakan penelitian deskriptif kuantitatif, dimana datanya berupa angkaangka dan dianalisis dengan teknik analisis statistik deskriptif. Guna melengkapi hasil analisis, disajikan juga analisis kuantitatif sebagai pelengkap. Berdasarkan nilai rata-rata unsur dari masing-masing pelayanan pada unit layanan Penyelenggara Haji dan Umroh Kantor Kementerian Agama Kota Banjarbaru didapatkan hasil penelitian pengukuran Indeks Kepuasan Masyarakat (IKM) yang menunjukkan kualitas pelayanan dengan nilai IKM setelah dikonversikan yaitu 80,69 dan berada pada kategori "BAIK”..
\end{abstract}

Keywords: Kepuasan Masyarakat, Indeks, Layanan, Publik

\begin{abstract}
Community satisfaction is a very important factor and determines the success of a government agency in providing services to the community because the community is a consumer of the product or service it produces. The purpose of this study is to analyze the quality of services provided by the Hajj and Umrah service units of the Banjarbaru City Ministry of Religion Office to the public or the public and to determine the level of appropriateness between service performance and expectations or the level of community interest. This research is a quantitative descriptive study, where the data is in the form of numbers and analyzed with descriptive statistical analysis techniques. To complement the results of the analysis, quantitative analysis is also presented as a complement. Based on the average value of the elements of each service unit in the service unit of Hajj and Umrah Pilgrims Office of the Ministry of Religion in Banjarbaru City, the results of the measurement study of the Community Satisfaction Index (IKM) which shows the quality of service with the value of the IKM after being converted is 80.69 and are at the "GOOD" category.
\end{abstract}

Kata Kunci : Community Satisfaction Index, Service, Public 


\section{PENDAHULUAN}

Dalam menjalankan tugasnya keberadaan birokrasi pemerintahan menjadi suatu yang tidak bisa ditawar-tawar lagi dan mereka akan selalu menentukan aktifitas mereka (Kumorotomo dan Margono, 1994). Pelayanan publik adalah Setiap kegiatan yang dilakukan oleh pemerintah terhadap sejumlah manusia yang memiliki setiap kegiatan yang menguntungkan dalam suatu kumpulan atau kesatuan, dan menawarkan kepuasan meskipun hasilnya tidak terikat pada suatu produk secara fisik (Harbani Pasolong (2007:128), Masyarakat berhak untuk mendapatkan pelayanan yang terbaik dari pemerintah karena masyarakat telah memberikan dananya dalam bentuk pembayaran pajak, retribusi dan berbagai pungutan lainnya (Mahmudi, 2005). Pendapat tersebut mengisyaratkan betapa besarnya peran dan fungsi pemerintah dalam pemenuhan kebutuhan masyarakat, sebagai perwujudannya pemerintah wajib memberikan pelayanan terbaik kepada masyarakat (public Service) dengan orientasi dan penekanan kepada mendahulukan kepentingan publik, mempermudah proses, mempersingkat prosedur dan biaya yang ringan (Zaini Rohmad, dkk., 2015).

Pelayanan prima yang diberikan oleh petugas pelayanan unit layanan penyelenggara haji dan umroh sangat berpengaruh terhadap kualitas pelayanan yang dirasakan oleh masyarakat yang dilayani. Kualitas pelayanan merupakan salah satu faktor penentu dalam keberhasilan pemberian pelayanan oleh Dinas/Instansi maupun petugas pelayanan. Semakin masyarakat merasa puas dilayani maka semakin berkualitas pelayanan yang diberikan oleh Dinas/Instansi atau petugas pelayanan kepada masyarakat (Nurhasanah Ningrum, 2018).

Berdasarkan uraian diatas maka perumusan masalah dalam penelitian ini adalah "Berapakah nilai indeks kepuasan masyarakat terhadap pelayanan publik pada unit layanan Penyelenggara Haji dan Umroh Kantor Kementerian Agama Kota Banjarbaru?" sehingga tujuan dari penelitian ini yaitu untuk mengetahui indeks kepuasan masyarakat terhadap pelayanan publik pada unit layanan Penyelenggara Haji dan Umrah Kantor Kementerian Agama Kota Banjarbaru.

\section{METODE}

Menurut Ratminto dan Atik Septi (2010: 5) pelayanan publik atau pelayanan umum adalah: "Segala bentuk jasa pelayanan, baik dalam bentuk barang publik maupun jasa publik yang pada prinsipnya menjadi tanggung jawab dan dilaksanakan oleh Instansi Pemerintah di Pusat, di Daerah, dan di lingkungan Badan Usaha Milik Negara atau Badan Usaha Milik Daerah, dalam rangka upaya pemenuhan kebutuhan masyarakat maupun dalam rangka pelaksanaan ketentuan perundang-undangan”.

Kepuasan pelayanan adalah hasil pendapat dan penilaian masyarakat terhadap kinerja pelayanan yang diberikan oleh aparatur penyelengara pelayanan publik. Unsur pelayanan adalah faktor atau aspek yang terdapat dalam penyelenggara pelayanan kepada masyarakat (Nurhasanah Ningrum, 2018). Pelayanan publik (public services) oleh birokrasi publik merupakan salah satu perwujudan dari fungsi aparatur Negara sebagai abdi masyarakat disamping sebagai abdi negara. Pelayanan publik oleh birokrasi publik dimaksudkan untuk mensejahterakan rakyat (Zainuddin, 2016). Kualitas pelayanan publik yang baik tercermin dari komitmen organisasi penyelenggara (Saputra, 2014). Sehingga pelayanan publik dapat diartikan sebagai pemberian layanan (melayani) keperluan orang atau masyarakat yang mempunyai kepentingan pada organisasi itu sesuai dengan aturan pokok dan tata cara yang telah ditetapkan (Moleong, 2004: 97).

Kepuasan pelanggan menurut Gotleb, Grewal dan Brown (Tjiptono, 2004: 147) merupakan respon afektif terhadap pengalaman melakukan konsumsi yang spesifik, lebih lanjut menurut Tse dan Wilton (dalam Tjiptono, 2004: 146) disebutkan bahwa kepuasan atau ketidakpuasan pelanggan adalah respon 
pelanggan terhadap evaluasi ketidaksesuaian yang dirasakan antara harapan sebelumnya dan kinerja aktual produk setelah pemakainnya.

Menurut Iskandar (2005:174) Penelitian deskriptif adalah penelitian yang ada hubungannya dengan pemaparan suatu penomena atau hubungan antara dua atau lebih fenomena, dan metode ini sering kali menggunakan teknik survey. Sedangkan menurut pendapat Whitney (1960) metode deskriptif adalah pencarian fakta dengan interpretasi yang tepat. Penelitian deskriptif mempelajari masalah-masalah dalam masyarakat, serta tata cara yang berlaku dalam masyarakat serta situasi-situasi tertentu, termasuk tentang hubungan, kegiatan-kegiatan, sikap-sikap, pandangan-pandangan serta proses-proses yang sedang berlangsung dan pengaruh-pengaruh dari suatu fenomena

Menurut Sugiyono (2013:27) Metode pengumpulan data adalah : "Metode pengumpulan data adalah Penelitian lapangan (Field Research), dilakukan dengan cara mengadakan peninjauan langsung pada instansi yang menjadi objek untuk mendapatkan data primer dan sekunder”.

Instrumen penelitian ini adalah kuesioner pilihan dengan menggunakan skala likert. Skala diukur dengan melihat variabel dependen IKM dan varibel independen yang terdiri dari 9 unsur; persyaratan (U1, prosedur (U2), waktu pelayanan (U3), biaya/tarif (U4), produk spesifikasi jenis pelayanan (U5), kompetensi pelaksana (U6), perilaku pelaksana (U7), maklumat pelayanan (Penanganan Pengaduan, Saran dan Masukan) (U8), serta penanganan pengaduan, saran dan masukan (U9). Data yang dikumpulkan dalam penelitian ini merupakan data primer, yaitu data yang diperoleh secara langsung dari responden melalui face to face untuk melakukan interview dengan mengisi kuesiner secara terstruktur. Kuesioner dibagikan ke responden setelah responden menerima pelayanan di unit layanan Penyelenggara Haji dan Umrah. Analisis data dibagi ke dalam tiga tahap. Tahap pertama kuesioner yang sudah diisi dilakukan pembersihan dan diberi koding. Jawabannya sesuai unsur penilaian skala likert dengan kategori tidak baik diberi persepsi 1, kurang baik diberi persepsi 2, baik diberi persepsi 3, dan sangat baik diberi persepsi 4. Tahap kedua dilakukan entry data dengan memasukkan data ke dalam sheet tabel isian yang terdiri dari 9 kategori pelayanan. Tahap ketiga menghitung nilai rata-rata per unsur kategori pelayanan dengan penilaian setiap unsur dari masing-masing pertanyaan yang diajukan kepada responden. Nilai indeks unit pelayanan diperoleh dari penjumlahan 9 unsur nilai rata-rata terimbang. Indeks Kepuasan Masyarakat (IKM) diperoleh dari nilai indeks unit pelayanan dikali nilai dasar 25. Kategorisasi mutu pelayanan dapat dilihat sebagaimana tabel berikut ini.

Tabel 1.

Kategorisasi Mutu Pelayanan

\begin{tabular}{ccccc}
\hline NO & $\begin{array}{c}\text { NILAI } \\
\text { INTERVAL } \\
\text { (IKM) }\end{array}$ & $\begin{array}{c}\text { NILAI INTERVAL } \\
\text { KONVERSI (NIK) }\end{array}$ & $\begin{array}{c}\text { MUTU } \\
\text { PELAYANAN }\end{array}$ & $\begin{array}{c}\text { KINERJA UNTT } \\
\text { LAYANAN }\end{array}$ \\
\hline 1 & $1,00-2,596$ & $25,00-64,99$ & $\mathrm{D}$ & Tidak baik \\
2 & $2,60-3,064$ & $65,00-76,60$ & $\mathrm{C}$ & Kurang baik \\
3 & $3,064-3,532$ & $76,61-88,30$ & $\mathrm{~B}$ & Baik \\
4 & $3,5324-4,00$ & $88,31-100,00$ & $\mathrm{~A}$ & Sangat Baik \\
\hline
\end{tabular}




\section{HASIL DAN PEMBAHASAN}

\subsection{Hasil Penelitian}

Indeks Kepuasan Masyarakat (IKM) pada unit pelayanan Penyelenggara Haji dan Umrah Kantor Kementerian Agama Kota Banjarbaru diperoleh dari survei yang dilakasanakan pada bulan Januari sampai dengan Desember 2019 terhadap 300 responden, Karakteristik responden pada penelitian ini dikelompokkan menjadi 4 (empat) kategori, yakni kategori jenis kelamin, usia, jenis pekerjaan, dan tingkat pendidikan, seperti

yang tertera pada tabel 2 .

Tabel 2.

Karakteristik Responden

\begin{tabular}{|c|c|c|c|}
\hline & Karakateristik Responden & $\begin{array}{c}\text { Frekuensi } \\
(\mathbf{n}=\mathbf{3 0 0} \\
\text { responden) }\end{array}$ & $\%$ \\
\hline \multicolumn{4}{|c|}{ Jenis Kelamin } \\
\hline 1 & Perempuan & 170 & 57 \\
\hline 2 & Laki-laki & 130 & 43 \\
\hline \multicolumn{4}{|c|}{ Usia (Tahum) } \\
\hline 1 & $<18$ & 10 & 3 \\
\hline 2 & $18-27$ & 40 & 13 \\
\hline 3 & $28-37$ & 78 & 26 \\
\hline 4 & $38-47$ & 98 & 33 \\
\hline 5 & $48-57$ & 42 & 14 \\
\hline 6 & $>57$ & 32 & 11 \\
\hline \multicolumn{4}{|c|}{ Pendidikan } \\
\hline 1 & Tidak Sekolah & 27 & 9 \\
\hline 2 & $\mathrm{SD}$ & 2 & 1 \\
\hline 3 & SMP & 23 & 8 \\
\hline 4 & SMA & 84 & 28 \\
\hline 5 & DI/DII/DIII & 22 & 7 \\
\hline 6 & S1 & 115 & 38 \\
\hline 7 & $\mathrm{~S} 2$ & 26 & 9 \\
\hline 8 & $\mathrm{~S} 3$ & 1 & 0 \\
\hline \multicolumn{4}{|c|}{ Pekerjaaan } \\
\hline 1 & PNS/TNI/POLRI & 74 & 25 \\
\hline 2 & Pegawai Swasta & 55 & 18 \\
\hline 3 & Wiraswasta/Usahawan & 41 & 14 \\
\hline 4 & Pelajar/Mahasiswa & 33 & 11 \\
\hline 5 & Lainnya & 97 & 32 \\
\hline
\end{tabular}

Berdasarkan hasil data tabulasi indeks kepuasan tiap-tiap unsur pelayanan publik di unit layanan Penyelenggara Haji dan Umrah Kantor Kementerian Agama Kota Banjarbaru, dapat diketahui sebagaimana yang tersaji pada tabel 3 . 
Tabel 3.

Indeks Kepuasan Masyarakat

\begin{tabular}{llcc}
\hline No & \multicolumn{1}{c}{ Unsur Pelayanan } & $\begin{array}{c}\text { Nilai Per } \\
\text { Unsur }\end{array}$ & $\begin{array}{c}\text { Nilai Rata-Rata } \\
\text { Terimbang }\end{array}$ \\
\hline 1 & Persyaratan(U1) & 910 & 3,033 \\
2 & Sistem, Mekanisme, dan Prosedur (U2) & 941 & 3,137 \\
3 & Waktu Penyelesaian (U3) & 985 & 3,283 \\
4 & Biaya/Tarif(U4) & 1018 & 3,393 \\
5 & Produk Spesifikasi jenis pelayanan (U5) & 945 & 3,150 \\
6 & Kompetensi pelaksana (U6) & 1001 & 3,337 \\
7 & Perilaku pelaksana (U7) & 976 & 3,253 \\
8 & Penanganan Pengaduan, Saran dan Masukan (U8) & 985 & 3,283 \\
9 & Sarana dan Prasarana(U9) & 962 & 3,207 \\
\hline
\end{tabular}

Sebagaimana data tabel 4 tingkat kepuasan masyarakat masingmasing unsur sebagaimana tersaji berikut ini.

Tabel 4.

Tingkat Kepuasan Per Unsur Pelayanan

\begin{tabular}{llccc}
\hline No & \multicolumn{1}{c}{ Unsur Pelayanan } & $\begin{array}{c}\text { Nilai } \\
\text { IKM }\end{array}$ & $\begin{array}{c}\text { Nilai Konversi } \\
\text { IKM }\end{array}$ & $\begin{array}{c}\text { Mutu } \\
\text { Pelayanan }\end{array}$ \\
\hline 1 & Persyaratan (U1) & 3,033 & 75,825 & C \\
2 & Sistem, Mekanisme, dan Prosedur (U2) & 3,137 & 78,425 & B \\
3 & Waktu Penyelesaian (U3) & 3,283 & 82,075 & B \\
4 & Biaya/Tarif (U4) & 3,393 & 84,825 & B \\
5 & Produk Spesifikasi jenis pelayanan (U5) & 3,150 & 78,75 & B \\
6 & Kompetensi pelaksana (U6) & 3,337 & 83,425 & B \\
7 & Perilaku pelaksana (U7) & 3,253 & 81,325 & B \\
8 & Penanganan Pengaduan, Saran dan Masukan (U8) & 3,283 & 82,075 & B \\
9 & Sarana dan Prasarana (U9) & 3,207 & 80,175 & B \\
\hline
\end{tabular}

Sesuai dengan teori yang penulis gunakan, yaitu Peraturan Kepala BPN RI Nomor 5 Tahun 2012 tentang Petunjuk Teknis Pelaksanaan Pengadaan Tanah yang merupakan turunan dari Undang-Undang Nomor 2 Tahun 2012 tentang Pengadaan Tanah Bagi Pembangunan Untuk Kepentingan Umum. Di dalam petunjuk teknis pelaksanaan pengadaan tanah ini, lebih rinci dijelaskan bagaimana prosedur dalam pengadaan tanah yang dilaksanakan oleh Badan Pertanahan Nasional.

Secara umum, penulis melihat pelaksanaan pengadaan tanah untuk pembangunan jalan tol PadangSicincin di Kabupaten Padang Pariaman yang sudah terlaksana sampai dengan 4,2 km di Nagari Kasang sudah cukup baik, namun dalam prosesnya kendala utama yang dihadapi belum menemukan upaya yang maksimal karena kurangnya koordinasi dan komunikasi antar pihak terlibat dalam proses pengadaan tanah. 


\subsection{Pembahasan}

Dari data yang tersaji di atas, dapat disimpulkan bahwa masing-masing unsur pelayanan yang diajukan kepada responden masuk dalam kategori baik. Hal ini mengindikasikan bahwa sistem pelayanan di unit layanan Penyelenggara Haji dan Umroh Kantor Kementerian Agama Kota Banjarbaru sudah baik. Selain itu, data dapat dikatakan valid apabila semua sebaran responden berjalan secara maksimal. Bila dilihat dari unsur jenis kelamin, sebaran responden yang dimintai jawaban cukup komprehensif. Dengan perbandingan $57 \%$ untuk rasio perepuan dan $43 \%$ untuk rasio laki-laki dari jumlah total 300 responden.

Data pengguna layanan pada unit layanan Penyelenggara Haji dan Umroh Kantor Kementerian Agama Kota Banjarbaru ini cukup beragam. Keberagaman pengguna layanan diketahui dari berbagai jenis pekerjaan yang diujikan kepada responden. Mulai dari PNS/TNI/Polri, pegawai swasta, wiraswasta atau pengusaha, pelajar atau mahasiswa, dan lainnya. Jika kita lihat data jumlah frekuensi paling banyak, maka secara umum memang pelayanan di dominasi oleh kalangan masyarakat yang bekerja pada sektor lainnya.

Pengguna layanan di unit layanan Penyelenggara Haji dan Umroh Kantor Kementerian Agama Kota Banjarbaru dari setiap unsur menyatakan bahwa unsur persyaratan belum sesuai dengan harapan masyarakat. Hal tersebut dapat dilihat dari nilai IKM untuk persyaratan pelayanan sebesar 3,033 dengan nilai konversi IKM sebesar 75,82. Berdasarkan hasil ini dapat dianalisis bahwa persyaratan di unit layanan Penyelenggara Haji dan Umroh Kantor Kementerian Agama Kota Banjararu tergolong kurang baik. Akan tetapi, ada beberapa masyarakat menganggap persyaratan pelayanan kurang sesuai dengan jenis pelayanan yang diinginkan. Berdasarkan uraian tersebut, perlu dilakukan upaya peningkatan terhadap akses kemudahan persyaratan layanan.

Prosedur pelayanan memiliki nilai rata-rata terimbang sebesar 3,137 dengan nilai konversi IKM sebesar 78,425. Berdasarkan hasil penelitian ini menunjukkan bahwa prosedur di unit layanan Penyelenggara Haji dan Umroh Kantor Kementerian Agama Kota Banjarbaru berada pada tingkat "Baik" dengan nilai B. Masyarakat merasa sudah dipermudah dengan mendapatkan informasi mengenai prosedur pelayanan dan memahami prosedur atau tahapan alur pelayanan.

Dalam aspek kecepatan pelayanan menunjukkan kategori "Baik". Hal tersebut dapat dilihat dari nilai IKM kejelasan petugas pelayanan sebesar 3,283 dengan nilai konversi sebesar 82,075. Dari data ini menunjukkan bahwa kejelasan petugas pelayanan memiliki tugas dan fungsi pokok pekerjaan secara jelas. Walaupun ada beberapa hal yang perlu diperbaiki, yakni soal target kinerja dan waktu harus ditingkatkan.

Kewajaran biaya pelayanan dapat dilihat dari aspek nilai rata-rata terimbang sebesar 3,393 dengan nilai konversi 84,825. Data ini menunjukkan bahwa kewajaran biaya pelayanan Kewajaran biaya pelayanan dapat dilihat dari aspek nilai rata-rata terimbang sebesar 3,05 dengan nilai konversi 76,25. Data ini menunjukkan bahwa kewajaran biaya pelayanan di unit layanan Penyelenggara Haji dan Umroh Kantor Kementerian Agama Kota Banjarbaru "Baik". Hal tersebut memperlihatkan bahwa dari kesesuaian biaya, petugas dari unit layanan Penyelenggara Haji Dan Umrah Kantor Kementerian Agama Kota Banjarbaru memiliki komitmen menghindari pungli dalam melayani masyarakat sehingga biaya yang dibayarkan dengan yang ditetapkan sesuai.

Produk spesifikasi jenis pelayanan ini merupakan hasil layanan yang diterima dan diberikan sesuai dengan ketentuan yang telah ditetapkan. Produk layanan ini adalah hasil dari setiap spesifikasi dari jenis pelayanan yang diberikan. Hasil penelitian menunjukkan bahwa produk layanan yang diberikan dan diterima oleh masyarakat yang masuk dalam kategori "Baik". Hal tersebut dapat dilihat dari nilai IKM sebesar 3,150 dengan nilai 78,75. Data ini menunjukkan bahwa layanan yang diterima dan diberikan dari petugas unit layanan Penyelenggara Haji Dan Umrah Kantor Kementerian Agama Kota Banjarbaru baik.

Kompetensi pelaksana adalah kemampuan intelektualitas dan tingkat kemampuan administrasi petugas pelayanan unit layanan Penyelenggara Haji Dan Umrah Kantor Kementerian Agama Kota Banjarbaru dijabarkan dalam pernyataan mengenai keahlian petugas pelayanan dalam memberikan 
pelayanan kepada masyarakat. Hasil penelitian menunjukkan bahwa kemampuan petugas di unit layanan Penyelenggara Haji dan Umroh Kantor Kementerian Agama Kota Banjarbaru sudah baik. Hal tersebut dapat dilihat dari nilai IKM sebesar 3,37 dengan nilai konversi 83,425. Data ini menunjukan bahwa kemampuan petugas pelayanan sudah berjalan dengan baik. Walaupun ada sebagian masyarakat menganggap kemampuan petugas kurang dalam proses pelayanan. Maka perlu dilakukan upaya untuk terus meningkatkan kemampuan petugas pelayanan.

Perilaku pelaksana adalah sikap tugas dalam memberikan layanan baik dalam bentuk kesopanan maupun keramahan petugas unit layanan Penyelenggara Haji dan Umroh Kantor Kementerian Agama Kota Banjarbaru dijabarkan dalam pernyataan mengenai sikap dan perilaku petugas dalam memberikan pelayanan kepada masyarakat. Hasil penelitian menunjukkan bahwa kesopanan dan keramahan petugas pelayanan unit layanan Penyelenggara Haji dan Umroh Kantor Kementerian Agama Kota Banjarbaru sudah baik. Hal tersebut dapat dilihat dari nilai IKM sebesar 3,253 dengan nilai konversi 81,325. Data ini menunjukkan perilaku pelaksana petugas pelayanan di unit layanan Penyelenggara Haji dan Umroh Kantor Kementerian Agama Kota Banjarbaru sudah baik. Namun perlu dilakukan upaya untuk meningkatkan kesopanan dan keramahan petugas pelayanan, khususnya dalam pelayanan administrasi.

Hasil penelitian mengenai Penanganan Pengaduan, Saran dan Masukan di unit layanan Penyelenggara Haji dan Umrah Kantor Kementerian Agama Kota Banjarbaru menunjukkan hasil yang sudah baik. Hal tersebut dapat dilihat dari nilai IKM sebesar 3,283 dengan nilai konversi 82,075. Nilai ini masuk dalam kategori "Baik".

Pengaduan, saran dan masukan adalah tata cara pelaksanaan penanganan pengaduan dan tindak lanjut. Hal ini adalah salah satu perbaikan kinerja yang dilakukan oleh petugas di unit layanan Penyelenggara Haji dan Umrah Kantor Kementerian Agama Kota Banjarbaru. Maka pengaduan, saran dan masukan kepada penyelenggara pelayanan untuk melaksanaan menunjukkan kriteria "Baik". Hal tersebut dapat dilihat dari nilai IKM sebesar 3,207 dengan nilai konversi 80,175.

Dari semua hasil pembahasan pada penelitian ini, perlu kiranya melakukan interpretasi terhadap penilaian IKM antara rentang nilai 25-100. Dari hasil yang sudah tersaji di atas, penilaian nilai rata-rata tertimbang ( $\Sigma$ NRR tertimbang) di atas dikonversikan dengan nilai dasar 25 . Hasilnya menunjukan bahwa nilai rata-rata terimbang secara keseluruhan sebesar 3,207 dan dikonversikan menjadi 80,69. Data ini menunjukkan bahwa tingkat kepuasan masyarakat terhadap pelayanan publik di di unit layanan Penyelenggara Haji dan Umrah Kantor Kementerian Agama Kota Banjarbaru tergolong dengan nilai kinerja 'Baik'.Hasil analisis pada penelitian ini menunjukkan bahwa secara tatakelola birokrasi yang ada sudah berjalanan dengan baik. Hal ini dapat dilihat dengan rasio nilai tingkat kepuasan masyarakat terhadap pelayanan publik masuk kategori nilai 'B' atau penilaian persepsi baik

\section{KESIMPULAN}

Berdasarkan hasil perhitungan indeks kepuasan masyarakat yang telah dibahas di bab pembahasan, maka hasil perhitungan masing-masing unsur pelayanan sebanyak 9 unsur pelayanan dan didapatkan hasil untuk nilai indeks kepuasan masyarakat yang telah dikonversi sebesar 80,69 dan berada di kategori "Baik". Adapun nilai rata-rata indeks kepuasan masyarakat yang dikaji berdasarkan karakteristik responden sebesar 3,228 dan berada di kategori "Baik".

Tingkat kepuasan masyarakat terhadap pelayanan publik di Unit layanan Penyelenggara Haji dan Umrah Kantor Kementerian Agama Kota Banjarbaru sudah tergolong baik. Hal ini mengindikasikan bahwa masyarakat puas dengan kinerja yang sudah dijalankan oleh petugas di unit layanan tersebut. Selain itu, setiap unsur penilaian IKM semua masuk kategori baik, walaupun ada satu unsur yang nilainya kecil diantara yang lain, yakni unsur persyaratan. 


\section{SARAN}

Berdasarkan hasil perhitungan dari 9 unsur pelayanan di unit layanan Penyelenggara Haji dan Umroh Kantor Kementerian Agama Kota Banjarbaru kepada masyarakat ada 8 unsur layanan yang mendapatkan nilai "Baik" namun ada juga satu unsur layanan dengan nilai yang rendah yaitu pada unsur layanan persyaratan dengan kategori "Kurang baik" sehingga peneliti menyarankan agar unit layanan Penyelenggara Haji dan Umroh Kantor Kementerian Agama Kota Banjarbaru dapat mempertahankan dan meningkatkan pelayanan yang lebih baik lagi

\section{DAFTAR PUSTAKA}

[1] Iskandar, (2005), Manajemen Personalia. Jakarta: Ghalia Putri.

[2] Kumorotomo, W. dan S. A. Margono (1994). Sistem Informasi Manajemen: Dalam OrganisasiOrganisasi Publik, Gajah Mada University.

[3] Mahmudi, S. (2005). Manajemen Kinerja Sektor Publik: Akademi Manajemen Perusahaan YKPN, Yogyakarta.

[4] Moleong Lexy J. 2004, Metodologi Penelitian Kualitatif, Bandung: Remaja. Rosdakarya.

[5] Nurhasanah, N. (2018). "Manajemen Pelayanan Publik." Indeks Kepuasan Masyarakat Terhadap Pelayanan Publik Pada Dinas Kependudukan Dan Pencatatan Sipil Kabupaten Sumedang

[6] Pasolong, Harbani, (2007). "Teori Administrasi Publik, Alfabeta, Bandung. Sofian Efendi dan Masri Singarimbun, 1989”, Metode Penelitian Survey. Jakarta: LP3ES.

[7] Ratminto, dan Atik Septi Winarsia. (2010). Manajemen Pelayanan. Yogyakarta: Pustaka Pelajar.

[8] Ratminto, \& Winarsih, A. S. (2016). Manajemen Pelayanan. Yogyakarta: Pustaka Pelajar.

[9] Saputra, T., \& Herianto, M. (2014). Komitmen organisasi, keadilan organisasi, dan kualitas pelayanan. Jurnal Administrasi Pembangunan, 2(2), 127-134.

[10]Sugiyono. 2012. Memahami Penelitian Kualitatif. Bandung: ALFABETA

[11] Tjiptono, Fandy .2004, Manajemen jasa. Yogyakarta : Andi

[12] Whitney, F.L. 1960. The elements of Research Asian Eds. Osaka: Overseas Book Co.

[13] Zaini Rohmad, dkk. 2015. Resolusi Konflik Pengelolaan Air Di Wilayah PariwisataKabupaten Karanganyar. Laporan Penelitian, Unpublished. LPPM UNS Surakarta

[14] Zainuddin. 2016. Birokrasi dalam Pelayanan Publik. Ombak. Yogyakarta 